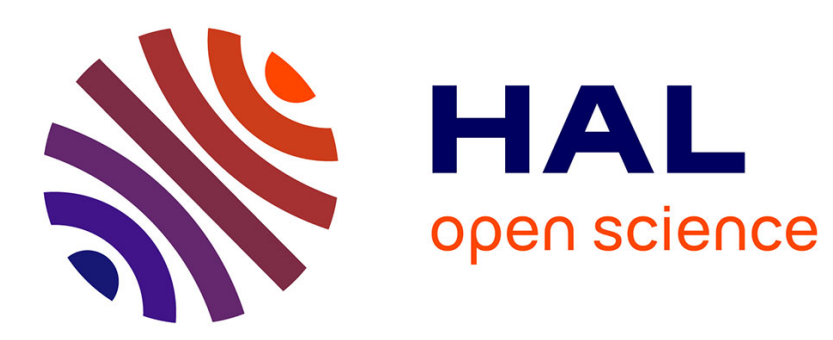

\title{
Investigation of metallic surface layers on metals by surface plasmon ATR spectroscopy
}

\author{
T. Lopez-Rios, F. Abelès, G. Vuye
}

\section{To cite this version:}

T. Lopez-Rios, F. Abelès, G. Vuye. Investigation of metallic surface layers on metals by surface plasmon ATR spectroscopy. Journal de Physique Lettres, 1979, 40 (14), pp.343-346. 10.1051/jphyslet:019790040014034300 . jpa-00231640

\section{HAL Id: jpa-00231640 https://hal.science/jpa-00231640}

Submitted on 1 Jan 1979

HAL is a multi-disciplinary open access archive for the deposit and dissemination of scientific research documents, whether they are published or not. The documents may come from teaching and research institutions in France or abroad, or from public or private research centers.
L'archive ouverte pluridisciplinaire HAL, est destinée au dépôt et à la diffusion de documents scientifiques de niveau recherche, publiés ou non, émanant des établissements d'enseignement et de recherche français ou étrangers, des laboratoires publics ou privés. 


\title{
Investigation of metallic surface layers on metals by surface plasmon ATR spectroscopy
}

\author{
T. Lopez-Rios, F. Abelès and G. Vuye \\ Laboratoire d'Optique des Solides (*), Université Pierre et Marie Curie, 75230 Paris Cedex 05, France \\ (Reçu le 14 mai 1979, accepté le 25 mai 1979)
}

\begin{abstract}
Résumé. - Les résultats optiques obtenus par une technique de réflexion totale, atténuée avec excitation d'ondes de plasma de surface sur des films très minces de $\mathrm{Ag}$, sur des surfaces de $\mathrm{Al}$, sont analysés dans le voisinage de la fréquence de plasma effective de l'Ag. On montre qu'il est nécessaire de tenir compte des effets non locaux (ondes de plasma longitudinales), et que la constante diélectrique complexe des films adsorbés est alors analogue à celle de l'Ag massif.
\end{abstract}

\begin{abstract}
The optical properties of very thin Ag layers on Al surfaces were investigated in the vicinity of the Ag effective plasma frequency, by attenuated total reflection with surface plasma wave excitation. The complex dielectric constant of the adsorbed layers is found to be similar to that of bulk Ag provided non-local effects (longitudinal plasma waves) are taken into account.
\end{abstract}

There has recently been an upsurge of interest concerning the properties related to the electronic structure of very thin metal films. Calculations have shown that a film a few monolayers thick has already the bulk density of states [1,2,3]. Photoemission experiments have confirmed this prediction $[4,5,6]$.

Optical spectroscopy of such films gives a large amount of information but it has not often been employed because of the experimental difficulties and the lack of valid models $[7,8]$. We will show that the use of a technique very sensitive to surface phenomena, combined with a refined analysis of the experimental results, proves to be a very powerful tool for the investigation of the electronic structure of thin metal layers adsorbed on a metal surface.

The experiments were carried out in a ultra-high vacuum system $\left(\sim 5 \times 10^{-10}\right.$ torr $)$ including an evaporation set-up for sample preparation and a double-beam spectrophotometer with a precision $\left(0.01^{\circ}\right)$ goniometer (giving the square of the reflection coefficient) for in situ attenuated total reflection (ATR) measurements. The samples were Al films deposited on a $60^{\circ}$ silica prism, subsequently covered with Ag superficial layers. The layer thickness was controlled in situ with a quartz microbalance calibrated by X-ray interference measurements [9] performed

(*) Equipe de Recherche Associée au C.N.R.S. nº 462. on thicker films. The modifications of the $68 \mathrm{eV} \mathrm{Al}$ and 351-356 eV Ag peaks in the Auger spectra recorded during Ag deposition suggested a continuous, monolayer by monolayer, growth ; the $\mathrm{Al}$ peaks disappeared for a coverage of about three Ag monolayers. Simultaneous measurements of the modifications of the underlying Al film electrical d.c. resistivity [10] during $\mathrm{Ag}$ deposition, as well as electron microscope investigations on the thickest $\mathrm{Ag}$ layer, confirmed a Van der Merwe mode of growth.

The experimental results reported hereafter were obtained with an Al film $220 \AA$ thick. Six Ag superficial layers, of $10,14,18,25,32$ and $56 \AA$ in thickness, were successively deposited and studied in the ATR configuration. Figure $1 a$ shows the experimental curves of the reflectivity $R_{\mathrm{p}}$ versus wavelength $\lambda$ obtained with an external angle of incidence $\varphi=37^{\circ} 22$. These curves are similar to those previously reported relative to the same $\mathrm{Ag} / \mathrm{Al}$ system [11]. For the thickest Ag superficial layers, they show two minima related to the splitting of the surface plasma wave (S.P.W.) dispersion relation around the effective Ag plasma frequency $\left(\hbar \omega_{\mathbf{p}}^{\mathbf{A g}}=3.77 \mathrm{eV}, \lambda_{\mathbf{p}}^{\mathrm{Ag}}=3280 \AA\right.$ ) [12]. For thinner superficial layers, a single minimum is displayed by the $R_{\mathrm{p}}(\lambda)$ curves. Figure $1 b$ shows the theoretical $R_{\mathrm{p}}(\lambda)$ curves computed with the expression for multilayer systems [13], taking for the superficial layers the bulk optical constants of $\mathrm{Ag}$ and the thickness $d_{\mathrm{f}}$ determined with the microbalance and 


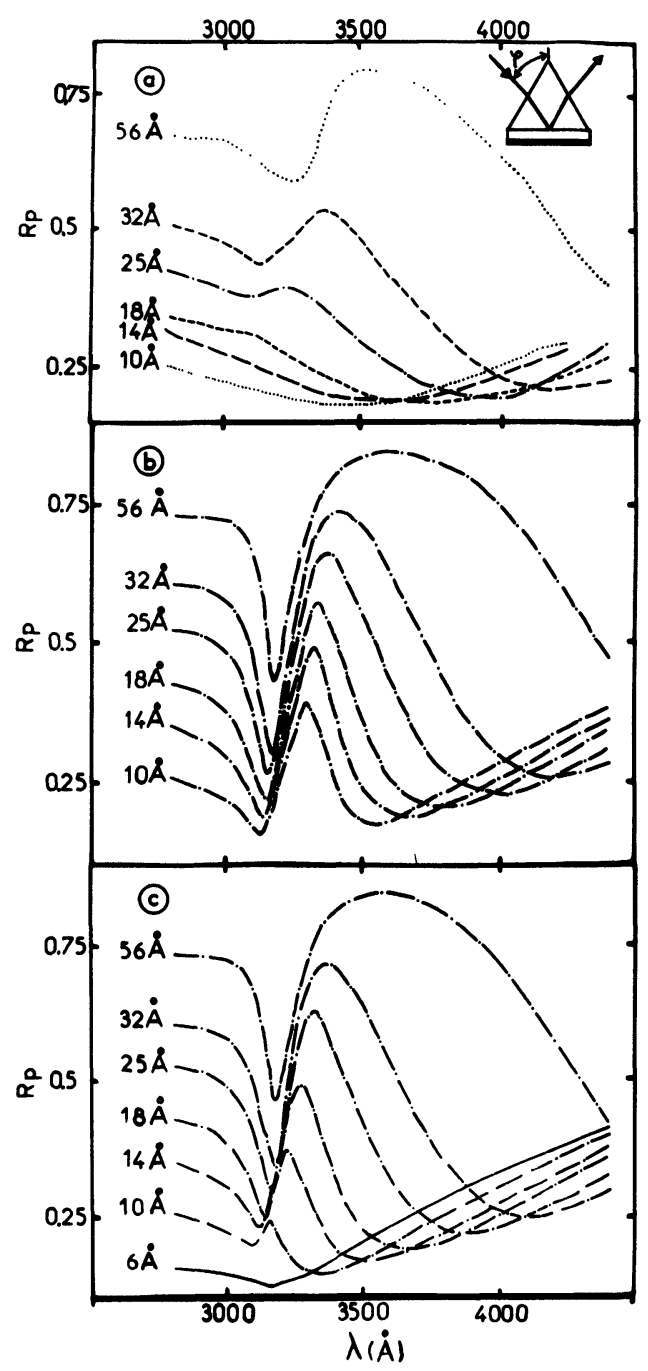

Fig. 1. - (a) Measured values of the reflectivity $R_{\mathrm{p}}$ for $\mathrm{Ag}$ layers of varying thickness on an $\mathrm{Al}$ film ( $220 \AA$ thick). The insert shows the experimental ATR set-up. (b) Calculated values of $R_{\mathrm{p}}$ for the same experimental arrangement; the classical Fresnel equations were used together with the bulk values for the dielectric constants of $\mathrm{Ag}$ and $\mathrm{Al}$. (c) Calculated values of $R_{\mathrm{p}}$ taking into account the longitudinal polarization wave propagating in the $\mathrm{Ag}$ layer.

for the underlying Al film the complex dielectric constant :

$$
\varepsilon=1-\left(\omega_{\mathrm{p}}^{\mathbf{A} \mathbf{l}}\right)^{2} / \omega\left(\omega+i \tau^{-1}\right)
$$

with $\hbar \omega_{\mathrm{p}}^{\mathbf{A l}}=15.5 \mathrm{eV}, \omega_{\mathbf{p}}^{\mathbf{A l}} \tau=20$ and the thickness $d=220 \AA$.

Two considerations can be put forward to explain the discrepancy between the experimental and the theoretical $R_{\mathrm{p}}(\lambda)$ curves : i) the $\mathrm{Ag}$ layers do not have the electronic structure of bulk $\mathrm{Ag}$ and optical constants different from the bulk ones should be taken for the computation; ii) films as thin as those investigated here are not well represented by a thin film model using a single local dielectric constant. Indeed non-local effects lead to small corrections to Fresnel equations $[14,15,16,17]$ but here we are dealing with a special situation $: a$ ) the observations are made in the vicinity of the Ag plasma frequency, a spectral region where longitudinal polarization waves (LPW) can propagate and spatial dispersion effects are important ; $b$ ) the experiments involve a resonant condition, which means that even small effects will induce important changes in the measured reflectivity.

We have tried to account for non-local effects in the following approximate way. The supporting medium (Al film) is represented by a single local complex dielectric constant $\varepsilon_{0}(\omega)$, and the $\mathrm{Ag}$ surface layer by transverse and longitudinal dielectric constants, both including additive contributions of free-electron intraband transitions $\left(\varepsilon^{c}\right)$ and d-electron interband transitions $\left(\varepsilon^{\mathrm{b}}\right): \varepsilon=\varepsilon^{\mathrm{c}}-1+\varepsilon^{\mathrm{b}}$. For the transverse dielectric constant, $\varepsilon^{\mathfrak{c}}$ was taken as

$$
\varepsilon_{\mathrm{T}}^{\mathrm{c}}=1-\omega_{\mathrm{p}}^{2} / \omega\left(\omega+i \tau^{-1}\right)
$$

with $\hbar \omega_{\mathrm{p}}=9.5 \mathrm{eV}$ and $\omega_{\mathrm{p}} \tau=230$ taken from the optical data of reference [18]. For the longitudinal dielectric constant, $\varepsilon^{\mathrm{c}}$ was approximated by [17] :

$$
\varepsilon_{\mathrm{L}}^{\mathrm{c}}=1-\frac{\omega_{\mathrm{p}}^{2}}{\omega\left(\omega+i \tau^{-1}\right)}\left[1+\frac{3}{5} v_{\mathrm{F}}^{2} \frac{K_{\mathrm{L}}^{2}}{\left(\omega+i \tau^{-1}\right)^{2}}\right],
$$

where $K_{\mathrm{L}}$ is the longitudinal wave vector and $v_{\mathrm{F}}=1.38 \times 10^{8} \mathrm{~cm} / \mathrm{s}$ the velocity of free electrons at the Fermi surface. The bound electron contribution $\varepsilon^{\mathrm{b}}$ was assumed to be local and values obtained by subtracting $\varepsilon^{\mathrm{c}}$ from the carefully determined $\mathrm{Ag}$ dielectric constant [18] were taken in both cases. The wave vector of the LPW is a solution of $\varepsilon_{\mathrm{L}}\left(\omega, K_{\mathrm{L}}\right)=0$, which, within the range of validity of the present approximation, leads to :

$$
K_{\mathrm{L}}^{2}=\frac{5}{3} \frac{1}{v_{\mathrm{F}}^{2}} \frac{\omega\left(\omega+i \tau^{-1}\right)^{3}}{\omega_{\mathrm{p}}^{2}} \varepsilon_{\mathrm{T}} .
$$

For the reflectivity of the $\mathrm{Ag}$ layers, we used an expression similar to that given in [17], taking into account the supporting plasma (Al film); the additional boundary condition, which in [17] expresses the continuity of the normal component of the electric field, i.e. $\left(E_{0}\right)_{\mathrm{n}}=(E)_{\mathrm{n}}$, was replaced by

$$
\varepsilon_{0}\left(E_{0}\right)_{\mathrm{n}}=\varepsilon^{\mathrm{b}}(E)_{\mathrm{n}}
$$

in order to consider both local dielectric constants $[19,20]$. Figure $1 c$ shows the $R_{\mathrm{p}}(\lambda)$ curves computed in this way for the six Ag layers under consideration. These curves still display two minima; however, curves presenting one minimum only are obtained for $d_{\mathrm{f}} \leqslant 6 \AA$. Generally speaking, taking into account non-local effects brings the theoretical curves closer to the experimental ones; in particular, it leads to a shift of the long wavelength minimum with thickness in agreement with the observed data. The remaining discrepancy between the curves of figures $1 a$ and $1 c$ is due to an additional damping related to the surface scattering of the conduction electrons of the $\mathrm{Ag}$ layer and will be discussed below. 


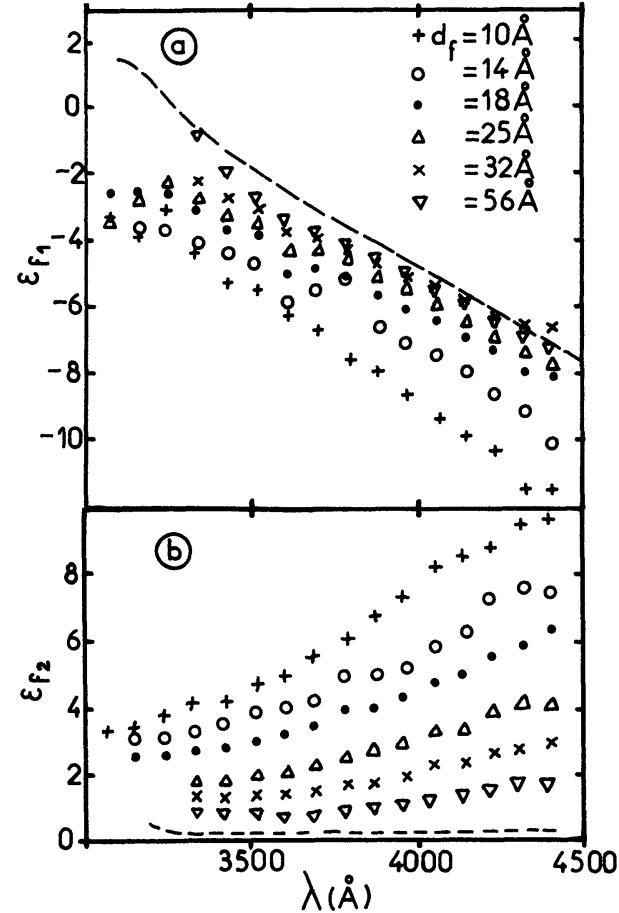

Fig. 2. - Real part $\varepsilon_{\mathrm{f} 1}(a)$ and imaginary part $\varepsilon_{\mathrm{f} 2}(b)$ of the dielectric constant of the investigated $\mathrm{Ag}$ layers $v s$. $\lambda$ in $\AA$ computed with the classical thin film formula.

Another approach to the problem consists in trying to determine the optical constants of the Ag surface layers from the whole set of optical data $\left(R_{\mathrm{p}}(\lambda)\right.$ for 14 different angles of incidence). Figures $2 a$ and $2 b$ show $\varepsilon_{\mathrm{f} 1}$ and $\varepsilon_{\mathrm{f} 2}$ versus $\lambda$ determined for the six Ag surface layers with the classical formula [13], the thickness $d_{\mathrm{f}}$ being taken equal to the values given by the microbalance. The $\varepsilon_{1}$ and $\varepsilon_{2}$ spectra for bulk $\mathrm{Ag}$ [18] are also indicated. The optical constants obtained for the superficial layers are appreciably different from the bulk ones, the deviation increasing with decreasing thickness. The $\varepsilon_{\mathrm{f} 2}$ behaviour suggests that the effective relaxation time of the conduction electrons is strongly reduced in the $\mathrm{Ag}$ layers, probably due to surface scattering combined with important size effects. However, this reduction of the relaxation time $\tau$ should have little influence on $\varepsilon_{1}$, which is dominated by $\omega_{\mathrm{p}}$, i.e. the number of conduction electrons per unit volume, and by the interband transition contribution, i.e. essentially the position of the d-band with respect to the Fermi level.

We tried again to determine the optical constants of the Ag superficial layers from the same set of data but with the expression for $R_{\mathrm{p}}$ taking into account the LPW. $K_{\mathrm{L}}$ in this expression was set equal to the values computed with the bulk $\mathrm{Ag}$ optical parameters. Indeed the LPW are expected to be much less sensitive to the above mentioned size effects, because their penetration depth is much smaller than for the usual transverse electromagnetic waves. Figure 3 shows the values of $\varepsilon_{\mathrm{f} 1}$ and $\varepsilon_{\mathrm{f} 2}$ obtained for the six layers, together with the bulk $\mathrm{Ag}$ values. The $\varepsilon_{\mathrm{f} 2}$ spectra are

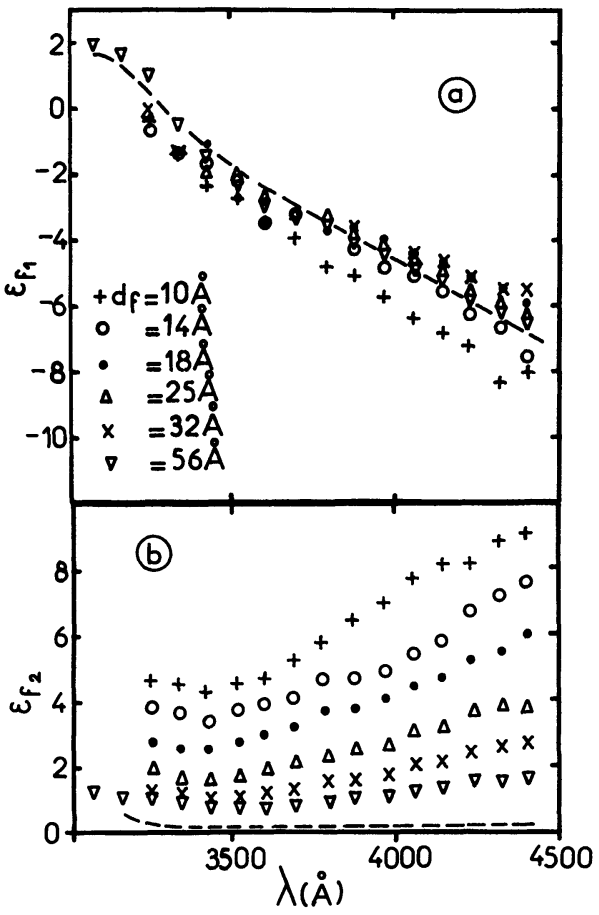

Fig. 3. - Real part $\varepsilon_{\mathrm{f} 1}(a)$ and imaginary part $\varepsilon_{\mathrm{f} 2}(b)$ of the dielectric constant of the investigated Ag layers $v s$. $\lambda$ in $\AA$ computed when the non-local effects are taken into account.

very similar to those of figure 2 , only slightly lowered (by about $10 \%$ ). The $\varepsilon_{\mathrm{f} 1}$ values are now the same for all films except the thinnest within experimental uncertainties, and are in good agreement with the bulk $\mathrm{Ag}$ values, especially in the immediate vicinity of the $\mathrm{Ag}$ plasma wavelength, where our expressions are most valid. The neglect of single particle excitations which become more important far away from the plasma wavelength [15] may explain the remaining discrepancy for the thinnest layer.

In conclusion, we have shown that purely optical measurements can test the possible modifications of the electronic structure of very thin metal layers. This was possible because we have used a very sensitive resonant technique : excitation of surface plasma waves by ATR, and because we have taken into account the excitation of longitudinal plasma waves in the analysis of the data. Our results on very thin $\mathrm{Ag}$ superficial layers on Al indicate that the optical constants of such layers are very close to those of bulk Ag. This is in agreement with the results obtained by low energy electron loss spectroscopy for $\mathrm{Ag}$ layers on $\mathrm{Si}$ [21] and by photoemission for $\mathrm{Ag}$ layers on $\mathrm{Cu}$ [5]. The observed decrease of the apparent relaxation time of the conduction electrons is certainly due to size effects related to the non-specularity of the surfaces of the $\mathrm{Ag}$ layers. It is difficult to proceed further with the analysis of the experimental data in the absence of a theory accounting more exactly for the influence of the surface scattering of the free electrons.

Acknowledgments. - We are deeply grateful to Dr. M. L. Thèye for advice and help. 


\section{References and footnotes}

[1] CoOper, B. R., Phys. Rev. Lett. 30 (1973) 1316

[2] Sohn, K. S., Dempsey, D. G., Kleinman, L. and CarUTHERS, E., Phys. Rev. B 13 (1976) 1515.

[3] Gay, J. G., Smith, J. R. and Arlinghaus, F. J., Phys. Rev. Lett. 38 (1977) 561.

[4] Eastmann, D. E. and Grobmann, W. R., Phys. Rev. Lett. 30 (1973) 177.

[5] Heimann, P., Neddermeyer, H. and Roloff, H. F., Proc. 7th Vac. Congr. and 3rd Intern. Conf. Solid Surfaces, Ed. R. Dobrozemsky, F. Rüdenauer, F. P. Viehböck, A. Breth, Vienna, 1977, p. 2145.

[6] Abbati, I., Braicovich, L., Bertoni, C. M., Calandra, C. and Manghi, F., Phys. Rev. Lett. 40 (1978) 469.

[7] Anderson, J., Rubloff, G. W., Passler, M. A. and Stiles, P. J., Phys. Rev. B 10 (1974) 2401.

[8] KolB, D. M., Advances in Electrochemistry and Electrochemical Engineering 11 (Wiley, N. Y.) 1978, p. 125.

[9] Umrath, W., Z. Angew. Phys. 22 (1967) 406.

[10] Pariset, C. and Cauvineau, J. P., Surf. Sci. 78 (1978) 478.

[11] Lopez-Rios, T., Abelès, F. and VuYe, G., J. Physique 39 (1978) 645.
[12] $\omega_{\mathbf{p}}^{\mathbf{A g}}$ and $\lambda_{\mathbf{p}}^{\mathbf{A g}}$ are the effective frequency and wavelength respectively, i.e. $\operatorname{Re}\left(\varepsilon^{\mathbf{A g}}\right)$ is then equal to zero, and are different from $\omega_{\mathrm{p}}$ and $\lambda_{\mathrm{p}}$ given below for which the free electron part only of $\varepsilon^{\mathrm{Ag}}$ becomes approximately equal to zero (Ehrenreich, H. and PhilipP, H. R., Phys. Rev. 128 (1962) 1622).

[13] Aвelès, F., in Advanced Optical Techniques, edited by A. C. S. van Heel (North-Holland Publishing Co., Amsterdam) 1967, p. 144.

[14] Forstmann, F., Z. Phys. 203 (1967) 495

[15] Fuchs, R. and Kliewer, K. L., Phys. Rev. 185 (1969) 905.

[16] Jones, W. E., Kliewer, K. L. and Fuchs, R., Phys. Rev. 178 (1969) 1201

[17] Melnyk, A. R. and Harrison, M. J., Phys. Rev. B 2 (1970) 835.

[18] Dujardin, M. M. and Theye, M. L., J. Phys. Chem. Solids 32 (1971) 2033

[19] Kliewer, K. L., Phys. Rev. B 14 (1976) 1412.

[20] A similar boundary condition was used for the $\mathrm{Ag} /$ vacuum interface.

[21] Derrien, J., Lelay, G. and Salvan, F., J. Physique Lett. 39 (1978) L-287. 